\title{
AVALIAÇÃO DA MICROBIOTA BACTERIANA CONJUNTIVAL DE CÃES HÍGIDOS atendidos no Hospital Veterinário da Universidade de Marília
}

\author{
Evaluation of the conjunctival bacterial microbiota of healthy \\ dogs treated at the Veterinary Hospital of Universidade de \\ Marilia
}

\author{
Elisa Rita de Oliveira Pereira ${ }^{1}$ (D) Laine Andreotti de Almeida², Milena Friolani ${ }^{3}$ \\ *Autor Correspondente: Elisa Rita de Oliveira Pereira. Rua João Fernandes, 441, Jardim \\ Pérola, Marília, SP. CEP: 17505-480. \\ E-mail: elisaoliveirapereira@hotmail.com
}

\begin{abstract}
Como citar: PEREIRA, E. R. O.; ALMEIDA, L. A.; FRIOLANI, M. Avaliação da microbiota bacteriana conjuntival de cães hígidos atendidos no Hospital Veterinário da Universidade de Marília. Revista de Educação Continuada em Medicina Veterinária e Zootecnia do CRMV-SP, São Paulo, v. 19, n. 1, 2021. DOl: https://doi. org/10.36440/recmvz.v19i1.38150.

Cite as: PEREIRA, E. R. O.; ALMEIDA, L. A.; FRIOLANI, M. Evaluation of the conjunctival bacterial microbiota of healthy dogs treated at the Veterinary Hospital of Universidade de Marilia. Journal of Continuing Education in Veterinary Medicine and Animal Science of CRMV-SP, São Paulo, v. 19, n. 1, 2021. DOI: https://doi. org/10.36440/recmvz.v19i1.38150.
\end{abstract}

\section{Resumo}

A microbiota conjuntival dos cães é formada por uma associação de micro-organismos normalmente não patogênicos, que interagem com o sistema imune do animal e possui função de atuar como barreira natural contra entrada de agentes patogênicos. O presente trabalho foi delineado para investigar os micro-organismos presentes na conjuntiva de cães sadios. Foram utilizados 25 cães sadios da rotina clínico cirúrgica do hospital veterinário da Unimar e após instilar uma gota de colírio anestésico em cada olho colheu-se amostra conjuntival superior e inferior de ambos os olhos com swab etéril, preservando a amostra em meio Stuart e logo após cultivada em meios BHI (Brain Heart Infusion), Ágar sangue de carneiro 6\%, Ágar MacConkey e Ágar TSA. Após o crescimento bacteriano foi realizada a identificação dos micro-organismos cultivados por meio de testes de triagem bioquímica como oxidase e catalase, além da análise da morfologia bacteriana em lâmina, padrão e coloração de crescimento em ágar. Houve crescimento bacteriano em amostras colhidas de 20 animais das quais $38 \%$ dos isolados foram compatíveis com S. intermedius; $30 \%$ de Bacilo sp. e 10\% S. aureus. A espécie Staphylococcus sp. é natural de membranas mucosas, não sendo

\footnotetext{
1 Aprimoranda em Clínica Cirúrgica e Anestesiologia de Pequenos Animais, Universidade de Marília, Marília, SP, Brasil

2 Aprimoranda em Saúde Pública, Instituto Adolfo Lutz, São Paulo, SP, Brasil

3 Especialista em Oftalmologia, docente da Universidade de Marília, Curso de Medicina Veterinária, Marília, SP, Brasil
} 
patogênica ao animal. Foi, portanto, constatada a predominância de S. intermedius nas amostras da microbiota do olho dos cães sadios examinados.

Palavras-chave: Bactéria. Conjuntiva. Cão. Microbiota.

\section{Abstract}

The conjunctival microbiota of dogs is formed by an association of normally non-pathogenic microorganisms, which interact with the animal's immune system and have the function of acting as a natural barrier against the entry of pathogens. The objective of the present investigation was the isolation of microorganisms from the conjunctiva of healthy dogs. Twenty five healthy dogs from the clinical surgical routine of the veterinary hospital of Unimar were investigated after instilling a drop of anesthetic eye drops in each eye, an upper and lower conjunctival a sample was collected from both eyes with an sterile swab, preserving the sample in Stuart's and immediately afterwards grown in BHI (Brain Heart Infusion), 6\% sheep blood agar, MacConkey agar and TSA agar. After bacterial growth, cultured microorganisms were identified by means of biochemical screening tests of oxidase and catalase, in addition to analysis of the bacterial morphology in the slide, pattern and growth stain on agar. It was isolated bacteria from eye samples of twenty animals, of them, $38 \%$ of isolates were compatible with S. intermedius; $30 \%$ of Bacilo sp. and $10 \%$ S. aureus. The species Staphylococcus sp. is native to mucous membranes and is not pathogenic to the animal. So it was found the predominance of $S$. intermedius in samples from the eye microbiota of the healthy dogs investigated.

Keywords: Bacteria. Conjunctiva. Dog. Microbiota.

\section{Introdução}

Uma associação de micro-organismos presentes na conjuntiva de um hospedeiro forma a microbiota conjuntival, que possui uma grande quantidade de nutrientes e vários microrganismos formadores da microbiota conjuntival normal. Os agentes que habitam a conjuntiva dos cães podem ser patogênicos ou não e normalmente são encontrados no ambiente em que vivem, interagindo com o sistema imune do animal e se mantendo estáveis em cães hígidos (GELLAT, 2003; SLATTER, 2005). A conjuntiva ocular, uma estrutura exposta e que possui contato com o meio externo, atua como barreira natural contra a entrada de agentes que possam causar danos ao organismo (GELLAT, 2003; SANTOS et al., 2017). Os microrganismos que colonizam a conjuntiva se estabelecem logo após o parto e modificam-se ao longo da vida do animal em virtude de fatores como o ambiente em que vive, nutrição que recebe, traumas e variações de imunidade fazendo com que a microbiota bacteriana seja definida pela integridade das barreiras anatomofisiológicas e respostas do sistema imunológico (GELLAT, 2003; SLATTER, 2005).

0 presente trabalho foi delineado para isolar e identificar os microrganismos bacterianos presentes na microbiota conjuntival de cães clinicamente sadios atendidos no Hospital Veterinário da Universidade de Marília.

\section{Material e métodos}

O presente trabalho foi aprovado pelo Comitê de Ética de Uso Animal da Universidade de Marília (Unimar) sob o parecer de número 23.2018.2. Foram utilizados, aleatoriamente, 25 cães sadios entre machos e fêmeas, de idades diferentes e sem raça definida, provenientes da rotina cirúrgica de castração eletiva do Hospital Veterinário da Unimar. As amostras foram colhidas de animais sadios, livres de doenças sistêmicas, no período de fevereiro a abril de 2019, necessitando de contenção mínima do paciente, sendo um procedimento rápido e indolor. Após exame clínico do animal, com mãos enluvadas estéreis, instilou-se uma gota de colírio anestésico (ANESTALCON®) em cada olho do animal, para promover a 
anestesia local das estruturas oculares e com swab estéril foi colhida uma amostra de conjuntiva ocular superior e inferior de ambos os olhos fazendo movimentos de rotação sem haver contato com a córnea e anexos externos como pálpebras e cílios. 0 colírio anestésico utilizado foi escolhido em virtude de ser uma solução de uso rotineiro em exames oftálmicos, para evitar desconforto ao animal.

As amostras foram preservadas em meio Stuart até o processamento no laboratório clínico da Universidade. Posteriormente, o material foi semeado em meio BHI (Brain Heart Infusion), meio universal para crescimento bacteriano, a temperatura de $37^{\circ} \mathrm{C}$ em estufa por 18 horas e após observação de turbidez do liquido indicando presença bacteriana, o conteúdo foi cultivado em ágar sangue de carneiro 6\%, para a observação do padrão de crescimento bacteriano, bem como morfologia e coloração de micro-organismos aeróbicos e anaeróbicos. 0 material também foi semeado em ágar MacConkey, ágar seletivo para bactérias gran-negativas e ágar TSA (Agar Triptona de Soja) para cultivo de microorganismos aeróbicos e anaeróbicos, os três meios de cultivo foram incubados em estufa a $37{ }^{\circ} \mathrm{C}$ por 24 horas.

Ao término do período de incubação foram realizados os testes bioquímicos de triagem para identificação bacteriana iniciando-se pelo teste de catalase (QUINN, 2018). Uma amostra do cultivo bacteriano retirada do Ágar sangue foi colocada em uma lâmina de vidro e foi instilada uma gota de peróxido de hidrogênio a 3\%, observando-se a formação de bolhas de ar indicativo de teste positivo para catalase e negativo quando não há formação de bolhas. Prosseguiu-se para o teste de oxidase (QUINN, 2018), no qual foram utilizadas tiras de papel filtro umedecidas com solução de oxalato de p-aminodimetilanilina a 1\% em lâmina de vidro e a partir do crescimento em TSA, esfregou-se uma alçada da massa bacteriana no papel de filtro umedecido e fez-se a leitura do resultado em um minuto. Também foi realizada a análise morfológica bacteriana em lâmina, após fixação e coloração de GRAM, bem como análise macroscópica de coloração e padrão de crescimento nos meios de cultivo.

A análise estatística empregada foi o método de frequência absoluta (Fi) e frequência relativa (Fri), onde o conjunto de diferentes valores da variável corresponde à frequência absoluta e percentagem dos mesmos correspondem à frequência relativa.

\section{Resultados e discussão}

Obteve-se $78 \%$ de crescimento bacteriano, onde de todos micro-organismos cultivados $90 \%$ foram gram positivos. Dentre as bactérias que apresentaram crescimento houve predominância da espécie Staphylococcus intermedius, seguido de Bacilo sp, conforme disposto no Quadro 1. As bactérias que se apresentaram como gram negativas eram em sua totalidade Bacilo sp, como disposto no Quadro 2. 0 gênero Staphylococcus foi a predominante durante o experimento.

Quadro 1 - Bactérias isoladas da conjuntiva de 25 cães saudáveis atendidos no Hospital Veterinário da Universidade de Marília, estado de São Paulo, Brasil, no período de fevereiro a abril de 2019

\begin{tabular}{|c|c|c|}
\hline CÃo & Bactéria isolada em Olho Direito & Bactéria isolada em Olho Esquerdo \\
\hline $\mathbf{1}$ & S. intermedius & S. intermedius \\
\hline $\mathbf{2}$ & S. Aureus & S. intermedius \\
\hline $\mathbf{3}$ & Bacilo sp. & Ausência de crescimento \\
\hline $\mathbf{4}$ & Bacilo sp. & S. intermedius \\
\hline $\mathbf{5}$ & Ausência de crescimento & S. Aureus \\
\hline $\mathbf{6}$ & Ausência de crescimento & Bacilo sp. \\
\hline
\end{tabular}




\begin{tabular}{|l|c|c|}
\hline $\mathbf{7}$ & S. Aureus & Ausência de crescimento \\
\hline $\mathbf{8}$ & Bacilo sp. & Ausência de crescimento \\
\hline $\mathbf{9}$ & Bacilo sp. & Bacilo sp. \\
\hline $\mathbf{1 0}$ & Ausência de crescimento & Ausência de crescimento \\
\hline $\mathbf{1 1}$ & Bacilo sp. & Bacilo sp. \\
\hline $\mathbf{1 2}$ & S. Aureus & Bacilo sp. \\
\hline $\mathbf{1 3}$ & Ausência de crescimento & S. intermedius \\
\hline $\mathbf{1 4}$ & S. Aureus & Ausência de crescimento \\
\hline $\mathbf{1 5}$ & S. intermedius & S. intermedius \\
\hline $\mathbf{1 6}$ & S. intermedius & S. intermedius \\
\hline $\mathbf{1 7}$ & Ausência de crescimento & Bacilo sp \\
\hline $\mathbf{1 8}$ & S. intermedius & Bacilo sp \\
\hline $\mathbf{1 9}$ & Ausência de crescimento & S. intermedius \\
\hline $\mathbf{2 0}$ & S. intermedius & S. intermedius \\
\hline $\mathbf{2 1}$ & Bacilo sp. & Bacilo sp. \\
\hline $\mathbf{2 2}$ & S. intermedius & S. intermedius \\
\hline $\mathbf{2 3}$ & Bacilo sp. & Bacilo sp. \\
\hline $\mathbf{2 4}$ & S. intermedius & S. intermedius \\
\hline $\mathbf{2 5}$ & & \\
\hline
\end{tabular}

TFonte: Os autores (2021)

Quadro 2 - Bactérias isoladas da conjuntiva de 25 cães saudáveis atendidos no Hospital Veterinário da Universidade de Marília, estado de São Paulo, Brasil, no período de fevereiro a abril de 2019

\begin{tabular}{ccc}
\hline MICROORGANIMOS ISOLADOS & FREQUÊNCIA DE ISOLAMENTO & $\%$ \\
\hline Staphylococcus intermedius & 19 & $38 \%$ \\
Bacilo sp. & 15 & $30 \%$ \\
Staphylococcus aureus & 5 & $10 \%$ \\
Ausência de crescimento & 11 & $22 \%$ \\
Total & 50 & $100 \%$ \\
\hline
\end{tabular}

TFonte: Os autores (2021)

O isolado de Staphylococcus intermedius e Staphylococcus aureus apresentou crescimento positivo em Ágar Sangue de carneiro, apresentando colônias esbranquiçadas e douradas respectivamente, de tamanho médio e produzindo hemólise dupla. Ambos foram identificados como micro-organismos anaeróbios facultativos com teste de catalase positivo e oxidase negativo. Ambos apresentaram crescimento negativo em Ágar MacConkey. 
As amostras identificadas como Bacilo sp. apresentaram crescimento positivo tanto em Ágar Sangue como em Ágar MacConkey, se dispondo em colônias grandes, formando cadeias. Nos testes bioquímicos se apresentaram positivas para catalase e oxidase. Todas as espécies isoladas apresentaram crescimento positivo em meio TSA.

O gênero Staphylococcus sp. que se arranja em cachos semelhantes a cachos de uva e no mínimo 30 espécies desse gênero se apresentam como comensais de pele e mucosas, podendo ser oportunistas e causarem infecções piogênicas de origem endógena ou exógena, usualmente associadas a trauma, imunossupressão, condições alérgicas, endócrinas e metabólicas (QUINN, 2018).

0 gênero Bacilo sp. são produtores de esporos e abrange mais de 50 espécies com características distintas, em sua grande maioria saprofíticas sem potencial patogênico, e amplamente distribuídas no ambiente (QUINN, 2018).

Os meios de preservação e cultivo se mostraram eficientes e de fácil manipulação, permitindo a identificação das bactérias isoladas. Em quatro animais houve distinção de bactérias isoladas em cada olho, sendo em três animais isoladas $S$. intermedius em um dos olhos e Bacilo sp. no outro e em um animal foi isolado $S$. intermedius em um olho e $S$. aureus no outro. Das bactérias gram negativas isoladas, em apenas um animal houve crescimento bacteriano gram negativo de um só olho.

Soluções oftálmicas em sua grande maioria possuem cloreto de bezalcônio em sua formulação, este conservante apresenta ação antimicrobiana devido ao seu efeito detergente sobre a parede celular da membrana bacteriana, fazendo com que haja diminuição da quantidade de células caliciformes da conjuntiva, aumentando a liberação de linfócitos e células de defesa, entretanto, isto somente se aplica ao uso crônico da substância (EPSTEIN et al., 2009; MASTROPASQUA et al., 2013).

Em animais sadios, livres de doenças sistêmicas a microbiota conjuntival tende a se manter estável, e o conhecimento dos micro-organismos presentes nesta microbiota é essencial para diagnóstico e tratamento de afecções oculares, uma vez que o uso excessivo de antimicrobianos pode contribuir para o desequilíbrio dessa microbiota, propiciando ocorrência de afecções (ANDRADE et al., 2002).

Santos et al. (2017) também observaram predominância no crescimento de S.intermedius nas culturas, bem como descrito por Oriá et al. (2013) com microbita ofltámica de cães sadios da cidade de Araçatuba, onde mais de $50 \%$ dos achados correspondiam a bactérias gram positivas. A predominância de bactérias gram positivas, principalmente do gênero Staphyloccocus sp. se justifica por serem microorganismos saprófitas naturalmente presentes em mucosas e pele, não havendo diferenças entre raça ou sexo do animal (ANDRADE et al., 2002; ORIÁ et al., 2013).

As pálpebras são estruturas oculares delimitadas internamente pela conjuntiva palpebral e revestidas externamente por pele e pelos fazendo com que o gênero Stapylococcus sp. possa estar presente na face externa das pálpebras de cães com ou sem sinais de conjuntivite e blefarite. Esse microorganismo também coloniza a pele humana saudável, sendo bem comum na região das mãos, contribuindo para a detecção comum de Staphylococcus spp. no microbioma ocular de cães (MAGGS, 2008; WATANABE et al., 2016).

As espécies de Bacilos também são consideradas normais no saco conjuntival, sendo isoladas em quantidade significativa (SANTOS et al., 2009). Os achados da predominância de S. intermedius, seguida por Bacilo sp. e S. aureus condiz com os achados observados por Haghkhah, Sarchahi e Molazem (2005) na Universidade Shiraz, no Irã, com amostras de cultivo bacteriano de conjuntiva de 60 cães sadios.

Monteiro et al. (2018) trabalharam com 104 cães na Universidade Federal do Mato Grosso, Brasil, dos quais 72 eram portadores de afecções oftálmicas, incluindo diferentes tipos de ceratite ulcerativa, em cultura de microbiota ocular, um total de $48,09 \%$ das bactérias isoladas também eram Staphyloccocus sp. seguido por Pseudomonas aeruginosa (16,01\%), Bacillus (9,92\%), Enterobacter (9,16\%), (6,87\%) e Escherichia coli (5,34\%), indicando que mesmo fazendo parte naturalmente da conjuntiva dos cães, em algumas situações esses microorganimos também podem estar envolvidos em afecções oculares, principalmente em ceratites ulcerativas não complicadas. 
Oriá et al. (2013) na Escola de Medicina Veterinária e Zootecnia da UFBA, Brasil, trabalhando com 30 cães clinicamente saudáveis e 28 com afecções oculares obtiveram 26,67\% de culturas negativas, isto é, ausência de crescimento em algumas amostras colhidas dos animais. Análise semelhantes utilizando cultura de microbiota oftálmica também obtiveram um percentual de culturas negativas em seus experimentos, assim como ocorrido em $22 \%$ das amostras do presente estudo (PRADO et al., 2005; WANG et al., 2008). Esta ausência não é totalmente justificada entre os autores, sendo explicada por variação de fatores com método de colheita, método de armazenamento e cultivo e swab utilizado.

\section{Conclusão}

Em cães sadios examinados no Hospital Veterinário da Universidade de Marília, estado de São Paulo, Brasil, no período de fevereiro a abril de 2019, houve a predominância no isolamento de Staphyloccus intermedius da microbiota ocular, totalizando $38 \%$ das culturas, sendo este um comensal natural da mucosa conjuntival dos cães. \&

\section{Referências}

ANDRADE, A. L. et al. Microbiota conjuntival de cães sadios da cidade de Araçatuba (SP). Arquivo Brasileiro de Oftalmologia, São Paulo, v. 65, n. 3, p. 323-326, 2002. DOl: https://doi.org/10.1590/ S0004-27492002000300008.

EPSTEIN, S. P. et al. Comparative toxicity of preservatives on immortalized corneal and conjunctival epithelial cells. Journal of Ocular Pharmacology and Therapeutics, [s.I.], v. 25, n. 2, p. 113-119, 2009. DOI: https://doi.org/10.1089/jop.2008.0098.

GELLAT, K. N. Manual de Oftalmologia Veterinária. São Paulo: Manole, 2003. 594 p.

HAGHKHAH, M.; SARCHAHI, A. A.; MOLAZEM, M. Conjunctival flora in normal dogs. Journal of Veterinary Research, [s.I.], v. 9, n. 2, p. 79-83, 2005. ISSN 1328-925X.

MAGGS, D. J. Ocular pharmacology and therapeutics. In: MAGGS, D. J.; MILER, P. E.; OFRI, R. (ed.).

Slatter's fundamentals of Veterinary Ophthalmology. 4th. ed. St Louis: Saunders, 2008. cap. 3, p. 33-61. ISBN: 9780721605616.

MASTROPASQUA, L. et al. Conjunctival goblet cells density and preservative-free tafluprost therapy for glaucoma: an in vivo confocal microscopy and impression cytology study. Acta Ophthalmologica, [s.l.], v. 91, n. 5, p. 397-405, 2013. DOl: https://doi.org/10.1111/aos.12131.

MONTEIRO, G. B. et al. Susceptibilidade antibiótica de isolados bacterianos em diferentes tipos de ceratites ulcerativas de cães na cidade de Cuiabá. Pesquisa Veterinária Brasileira, Rio de Janeiro, v. 38, n. 4, p. 726-733, 2018. DOI: https://doi.org/10.1590/1678-5150-PVB-4906.

ORIÁ, A. P. et al. Microbiota conjuntival em cães clinicamente sadios e com ceratoconjuntivite seca.

Ciência Animal Brasileira, Goiânia, v. 14, n. 4, p. 495-500, 2013. DOl: https://doi.org/10.5216/cab. v14i4.19210.

PRADO, M. R. et al. Survey of bacterial microorganisms in the conjunctival sac of clinically normal dogs and dogs with ulcerative keratitis in Fortaleza, Ceará, Brazil. Veterinary Ophthalmology, [s.l.], v. 8, n. 1, p. 33-37, 2005. DOl: https://doi.org/10.1111/j.1463-5224.2005.04061.x.

QUINN, P. J. et al. Microbiologia Veterinária: essencial. 2. ed. São Paulo: ARTMED, 2018. ISBN:

9788582714997. 
SANTOS, F. C. et al. Microbiota bacteriana conjuntival de cães portadores e não portadores de ceratoconjuntivite seca atendidos no Hospital Veterinário da Universidade Federal de Campina Grande. In: CONGRESSO BRASILEIRO ANCLIVEPA, 38., 2017, Recife. Anais [...] Recife: Anclivepa, 2017. p. 113.

SANTOS, L. G. F. et al. Microbiota conjuntival de cães hígidos e com afecções oftálmicas. Acta Scientiae Veterinariae, [s.I.], v. 37, n. 2, p. 165-169, 2009. DOI: https://doi.org/10.22456/1679-9216.16245.

SLATTER, D. Conjuntiva. In: SLATTER, D. Fundamentos de Oftalmologia Veterinária. 3. ed. São Paulo: Roca, 2005. p. 221-446. ISBN: 9788572415477.

WANG, L. et al. Investigation of bacterial microorganisms in the conjunctival sac of clinically normal dogs and dogs with ulcerative keratitis in Beijing, China. Veterinary Ophthalmology, [s.l.], v. 11, n. 3, p. 145-149, 2008. DOl: https://doi.org/10.1111/j.1463-5224.2008.00579.x.

WATANABE, K. et al. Methicillin-resistant Staphylococcus epidermidis is part of the skin flora on the hands of both healthy individuals and hospital workers. Biological \& Pharmaceutical Bulletin, Tokyo, v. 39, n. 11, p. 1868-1875, 2016. D0l: https://doi.org/10.1248/bpb.b16-00528. 